\title{
Fatigue behavior of basalt fiber-reinforced polymer tendons under a marine environment
}

Jianzhe Shi, Xin Wang, Zhishen Wu, Zhongguo Zhu

\begin{abstract}
Due to their advantageous mechanical behaviors and anti-salt properties, basalt fiber-reinforced polymer (BFRP) tendons are a promising prestressing component under a marine environment. However, the degradation law of fatigue behavior of BFRP tendons under a marine environment is still unclear. This paper studies the fatigue behavior of BFRP tendons after aging in a salt solution by temperature-accelerated experiments. The degradation mechanism of fatigue behavior is clarified based on previous studies and analysis of the failure mode. The effect of aging temperature on fatigue strength degradation is analyzed using both experimental data and scanning electron microscopy (SEM) images.
\end{abstract} Moreover, the fatigue strength degradation of BFRP tendons at different local temperatures was predicted according to the Arrhenius equation. The results show that the fatigue strength degradation of BFRP tendons is governed by the weakened fiber-matrix interface resulting from the hydrolyzation of $\mathrm{Si}-\mathrm{O}-\mathrm{Si}$ chemical bonds in salt solution. $\mathrm{SEM}$ showed that specimens aged at $55{ }^{\circ} \mathrm{C}$ for 63 days demonstrate increased corrosion than those in other groups. Through the Arrhenius equation, the fatigue strengths of BFRP tendons are predicted to be $0.41,0.43$ and $0.45 f_{u}$, respectively, at three representative northern latitudes after 100 years of aging in marine environments. The results provide guidance for fatigue design of BFRP tendons in a marine environment. 
23 Keywords: basalt fiber-reinforced polymer (BFRP) tendons; fatigue; marine environment; mechanism; Arrhenius equation; prediction

\section{Introduction}

27 In a marine environment, a variety of durability problems in traditional infrastructure arise due to the corrosion of steel; these problems severely lower the capacity and serviceability of structures and lead to excessive maintenance expenses [1-3]. Replacing steel materials with fiber-reinforced polymers (FRPs) is an effective means to overcome these problems. FRPs have been used in externally bonded strengthening or concrete-filled FRP tubes to prevent the penetration of chloride ions through concrete cracks [4, 5]. FRPs have also been applied in concrete structures to replace steel reinforcements [6]. Among the wide applications of FRPs, prestressing tendons are considered to be the most efficient utilization due to the extremely high strength of FRPs in the longitudinal direction of the fiber as well as a relatively low elastic modulus. Prestressed FRP tendons or cables are a promising material for the use in long-span structures, such as cable-stayed bridges or girder bridges [7]. Traditional FRPs include carbon FRP (CFRP), aramid FRP (AFRP) and glass FRP (GFRP), but some defects still exist in these types of FRPs, which limits their applications in civil engineering. For example, the costs of CFRP and AFRP are excessively high for infrastructure, and GFRP has poor chemical stability and mechanical properties. In recent years, a novel basalt fiber, i.e., a

42 type of inorganic fiber material, has been developed. This material is derived from a single raw material (molten volcanic rock) without any toxic gas emissions. Thus, it is considered to

44 be environmentally friendly in terms of its production and disposal process [8]. The 
mechanical properties (strength and modulus) and chemical stability of basalt FRP (BFRP) are significantly higher than those of GFRP [9]. In addition, the cost of BFRP is only about one-tenth to one-fifth of the costs of either AFRP or CFRP. Thus, a high cost-efficiency can be realized using BFRP. Moreover, BFRP tendons have a relatively high creep rupture stress equal to $0.52 f_{u}$ [10], which is comparable to CFRP $\left(0.7 f_{u}\right)$ and AFRP $\left(0.55 f_{u}\right)$ [11]. BFRP tendons can also survive 2 million cycles of fatigue load in the stress range of $0.55 f_{u}$ to $0.6 f_{u}$ [12]. In terms of the durability, BFRP has shown high strength retention of up to $95 \%$ after aging in salt corrosion for 240 days (d) [13]. Owing to the above advantages, BFRP shows promise for applications such as bridge cables or external prestressing tendons under a marine environment $[14,15]$. However, structures such as bridge girders strengthened by FRP tendons or cable-stayed bridges are often subjected to cyclic loads. Thus, a comprehensive understanding of the fatigue behavior degradation of BFRP tendon under seawater corrosion is necessary for its appropriate application in a marine environment.

\section{Review of previous work}

The fatigue behavior degradation of BFRP tendons under a marine environment is associated with two aspects. One is the fatigue behavior of BFRP in a non-corrosive environment, and the other is the degradation of the mechanical properties of BFRP under a marine environment. First, the authors have previously conducted a macroscopic study on the fatigue behavior of BFRP tendons using an effective anchorage through a winding fiber sheet [12]. S-N curves of BFRP tendons were plotted to predict the fatigue strength, and it was concluded that BFRP tendons remained undamaged within 2 million cyclic loads at the stress 

conducted by Zhao et al. [16], and the failure modes were divided into fiber rupture, fiber-matrix interface and matrix cracking at high, middle and low stress levels, respectively. From the S-N curves and the mechanism clarification in a non-corrosive environment, the degradation of fatigue strength and the failure mechanism with exposure to a salt solution can be analyzed.

Second, many studies in the literature discuss the degradation of the mechanical properties under a marine environment. BFRP exhibits satisfactory anti-salt properties because the chloride ions lower the $\mathrm{Fe}^{2+}$ content in the basalt fiber, leading to a higher stability of BFRP under a marine environment [17]. BFRP bars demonstrated only a $6 \%$ strength reduction after exposure to salt solution for 42 days at a relatively high temperature, $40{ }^{\circ} \mathrm{C}$ [18]. Furthermore, after aging in salt solution for 120 days under stress levels of 0.3 and $0.6 f_{u}\left(f_{u}=\right.$ tensile strength) at normal temperature, BFRP still exhibited $93 \%$ and $91 \%$ strength retentions, respectively [19]. The strength reduction of BFRP is mainly caused by local hydrolyzation of $\mathrm{Si}-\mathrm{O}-\mathrm{Si}$ chemical bonds between the fibers and the matrix [20]. Moreover, chloride ions have negligible effects on the degradation of BFRP in salt solution. However, the fatigue behavior in a salt solution is different from the short-term mechanical properties since cyclic loads may enlarge the effects of fiber-matrix interface corrosion. strength of BFRP tendons was reduced by $25 \%$ after aging for $70 \mathrm{~d}$ in a salt solution at room temperature. However, most of the specimens failed at the anchor zone; therefore, the results might not reflect the real fatigue behavior of the BFRP tendons themselves. Moreover, the 
effects of different aging temperatures and durations were not taken into consideration in El

90 Refai's research.

91 The current paper conducts fatigue tests on BFRP tendons after aging in a salt solution at

92 three different temperatures for three different time durations. The degradation mechanism of

93 fatigue behavior is clarified, and the effect of aging temperature on the fatigue strength

94 degradation is analyzed and discussed. Finally, the fatigue strength degradation of BFRP

95 tendons at different local temperatures is predicted with the Arrhenius equation. The results

96 act as a guide for the application of BFRP tendons under a marine environment.

\section{Experimental program}

99

\subsection{Material preparation}

100 The BFRP tendons adopted in this study were manufactured by 1200 tex unidirectional fiber

101 roving impregnated in epoxy resin through pultrusion. The fiber volume fraction was approximately $70 \%$. The diameter and total length of each specimen were $5.9 \mathrm{~mm}$ and 1000

$103 \mathrm{~mm}$, respectively.

104 Before the short-term and fatigue tests, the specimens were anchored using a special method.

105 Bi-directional basalt fiber sheets impregnated in vinyl ester resin were first winded on the

106 surface of the anchor zone (Figure 1(a)). Then, the anchor zone was placed into a specially

107 designed mold (Figure 1(b)) for compression molding at a constant temperature of $120{ }^{\circ} \mathrm{C}$ for

10830 minutes. The diameter and length of the anchorage were approximately $22 \mathrm{~mm}$ and 200

$109 \mathrm{~mm}$ after molding, respectively (Figure 1(c)). A conical transition section at the loading end

110 of the anchorage was designed to alleviate stress concentration (Figure 1(d)). This type of 
111 anchorage performed effective in preventing premature failure of BFRP tendons at the anchor

112 zone under cyclic loads [12].

\section{$114 \quad 3.2$ Test setup}

115 As shown in Figure 2, a SJY-II corrosion test chamber was adopted that contained a water

116 bath. Environmental chambers were placed in the water bath. The water bath provided a

117 constant aging temperature. The environmental chamber was $1200 \mathrm{~mm}$ long, $200 \mathrm{~mm}$ wide

118 and $500 \mathrm{~mm}$ deep, and it was used to contain the salt solution and specimens for aging.

119 Short-term tensile tests and fatigue tests were conducted using a LFV-1000 servo-hydraulic

120 dynamic fatigue tester (Figure 3 ). The tester has a loading capacity of $\pm 900 \mathrm{kN}$ and a

121 precision of $1 \%$. The strains of the specimens were measured by an extensometer with a

122 gauge length of $50 \mathrm{~mm}$. Load and strain data were recorded synchronously once per second

123 by a computer in short-term tensile tests.

\subsection{Aging procedure}

126 Although the BFRP tendons were subjected to the coupling effects of fatigue and a marine

127 environment in practical engineering, it is difficult to simulate these coupling effects in the

128 laboratory. The fatigue test after aging in salt solution can also reflect the degradation of

129 BFRP's fatigue behavior in salt solution, according to the research of El Refai [21]. Thus,

130 fatigue load was applied on the specimens after aging in salt solution in this study.

131 Forty-five specimens were first immersed in salt solution at temperatures of 25,40 and $55^{\circ} \mathrm{C}$

132 for aging durations of 21, 42 and $63 \mathrm{~d}$ before the fatigue test. The specimens were labeled as 
133 shown in Table 1. The letters " $T$ " and " $\mathrm{D}$ " in the group names represent temperature and day,

134 respectively. Temperatures of 25,40 and $55^{\circ} \mathrm{C}$ were adopted as the accelerated temperatures.

135 The aging durations had an interval of $21 \mathrm{~d}$ because conspicuous degradation of the tensile

136 strength was observed for BFRP at 3 weeks under an accelerated temperature in a previous

137 study [20].

138 The composition of the salt solution to simulate a marine environment was $24.53 \mathrm{~g} / \mathrm{L} \mathrm{NaCl}$,

$1395.20 \mathrm{~g} / \mathrm{L} \mathrm{MgCl} 2,4.09 \mathrm{~g} / \mathrm{L} \mathrm{Na}_{2} \mathrm{SO}_{4}$, and $1.16 \mathrm{~g} / \mathrm{L} \mathrm{CaCl}_{2}$, according to ASTM D1141-98 [22].

140 The solution was prepared using deionized water.

$142 \quad 3.4$ Loading procedure

143 Short-term tensile tests were conducted on five effective specimens without any failure at the

144 anchor zone. Loading was controlled by displacement with a rate of $0.15 \mathrm{~mm} / \mathrm{s}$. The elastic

145 modulus was calculated using the loads and the corresponding strains at approximately $50 \%$

146 and $20 \%$ of the ultimate tensile capacity, according to JSCE-E531 [23]. The measured tensile

147 strength of BFRP tendons served as the reference for stress levels in the fatigue tests

148 hereinafter.

149 The limit of the stress range of the BFRP tendons for 2 million cyclic loads is $0.05 f_{u}$

150 according to the experimental fitting in the authors' previous study [12]. A previous finite

151 element (FE) method also reported that the maximum stress range of the cables in

152 cable-stayed bridges was $57.3 \mathrm{MPa}$, equal to $0.035 f_{u}$ [24]. Thus, the fatigue tests were

153 conducted at a constant stress range of $0.05 f_{u}$ in the current study. The main variable in the

154 fatigue tests was the fatigue maximum stress. With reference to the authors' previous study 
155 [12], fatigue maximum stresses were determined to range from 0.6 to $0.7 f_{u}$, which ensured 156 that fatigue failure took place within 2 million cyclic loads. In the fatigue tests, the load was

157 first applied on a specimen at a rate of $0.3 \mathrm{kN} / \mathrm{s}$ up to the average cyclic load. Then, the cyclic 158 load was applied immediately and continuously with a sinusoidal wave until the specimen

159 failed. Fatigue tests were conducted with a frequency of $5 \mathrm{~Hz}$ according to JSCE-E 534 [25]

160 to avoid a temperature effect on fatigue behavior.

161

\section{4. Results and discussion}

\section{4.1 Short-term tensile properties}

164 The five specimens in the short-term tensile test all exhibited a typical dispersed failure of 165 fibers (Figure 4). No failure was observed at the anchor zone. The results of the short-term 166 tensile test are shown in Table 2. The high ultimate strength (1719 MPa) and low coefficient

167 of variation (CV) equal to $3.25 \%$ show the feasibility of BFRP tendons for prestressing 168 applications. The $95 \%$ guaranteed strength is calculated to be $1628 \mathrm{MPa}$ by $f_{k}=f_{m}-1.645 \sigma$,

169 where $f_{k}=$ standard value, $f_{m}=$ mean value, and $\sigma=$ standard deviation (SD) [26]. $f_{k}$ serves as $170 f_{u}$ hereinafter.

\subsection{Fatigue failure mode and fatigue lives}

173 In fatigue tests, the specimens exhibit a similar failure mode regardless of the fatigue load

174 level, aging duration or temperature. The initial failure appears at the surface of the BFRP

175 tendon specimen (Figure 5(a)) because the bundles of fibers near the surface are subjected to

176 a larger stress than the inner fibers due to the shear lag effect. The initial failure is caused by 
177 the debonding of the fiber-matrix interface, which is induced by the propagation of 178 micro-cracks in the matrix. As the initial failure appears and propagates, the cross-section of

179 the specimen decreases, which leads to a larger stress level in the specimen. Then, more 180 failure zones at the surface appear successively, and ultimate failure occurs [12]. The ultimate

181 failure mode, shown in Figure 5(b), is similar to that in the short-term tensile test (Figure 4).

182 No failure is observed at the anchor zone, demonstrating the effectiveness of the special

183 anchorage under cyclic load. The fatigue lives (total numbers of cycles at failure) of the 184 specimens are shown in Table 3 , in which $\sigma_{\max }$ and $N_{f}$ represent fatigue maximum stress and 185 fatigue life, respectively.

\subsection{Fatigue Degradation mechanism}

The fatigue failure of BFRP tendons at stress levels ranging from $0.6 f_{u}$ to $0.7 f_{u}$ is determined by the debonding of the fiber-matrix interface $[12,16]$. Thus, the mechanism of the fatigue degradation of BFRP after immersion in salt solution is explained based on fiber-matrix

191 interface degradation as follows. The surface of basalt fibers is treated with a coupling agent named $\gamma$-aminopropyl triethoxy (KH550). The coupling agent can establish a $\mathrm{Si}-\mathrm{O}-\mathrm{Si}$ chemical bond with basalt fibers, which is unstable in chemical solution [20]. After aging in

194 salt solution, the hydrones infiltrate through the gap between the macromolecules or 195 micro-cracks in the matrix and hydrolyze the $\mathrm{Si}-\mathrm{O}-\mathrm{Si}$ chemical bond between the fiber and the matrix [27], as expressed by

$$
[-\mathrm{Si}-\mathrm{O}-\mathrm{Si}-]+\mathrm{OH}^{-} \rightarrow[-\mathrm{Si}-\mathrm{OH}]+[-\mathrm{SiO}]^{-}
$$

198 Hydrolyzation leads to debonding of the fiber-matrix interface [28] (Figure 6). Thus, the 
weaker interface is vulnerable to cyclic loads and leads to a relatively shorter fatigue life compared to the specimens without any corrosion. However, this infiltration is so limited that only the fiber-matrix interfaces at the surface of the tendon are influenced.

\subsection{S-N curves}

Figure 7 shows the S-N curves of all test groups, along with the control group. A satisfactory linear relationship between the fatigue maximum stress and the logarithm of the fatigue life is observed from the data in each test group. The S-N curves of the groups aged in salt solution are slightly lower than the curve of the control group, showing the negative effect of salt solution on the fatigue behavior of BFRP tendons.

The semi-logarithmic relationship between the fatigue life and fatigue maximum stress is expressed by

$$
Y_{\sigma_{\max }}=a-b \ln N_{f}
$$

212 where $Y_{\sigma \max }=$ ratio of the maximum stress to ultimate strength; $N_{f}=$ fatigue life; $a$ and $b=$ 213 regression constants.

214 The fatigue strength is calculated by substituting $N_{f}=2 \times 10^{6}$ into Eq. (2). Values of the

215 fatigue strength of different test groups are shown in Table 4. Compared with the control 216 group, reductions in the fatigue strength are observed in the groups with aging in salt solution.

217 The group T55-D63 shows the largest reduction rate, which is equal to $13 \%$.

\subsection{Effect of aging temperature on the degradation law}

220 From the data in Table 4, the relationships between the fatigue strength and aging duration at 
221 three aging temperatures are shown in Figure 8. The curves at 25 and $40{ }^{\circ} \mathrm{C}$ show similar 222 tendencies. The fatigue strengths first decrease linearly from 0 to $42 \mathrm{~d}$, and no degradation is 223 observed from 42 to $63 \mathrm{~d}$ in these two curves, due to the decrease of infiltration rate with time 224 [28]. In contrast, for the curve at $55{ }^{\circ} \mathrm{C}$, the initial degradation rate is faster than the rates at 25 and $40{ }^{\circ} \mathrm{C}$, and the degradation continues from 42 to $63 \mathrm{~d}$. This phenomenon demonstrates that high temperature up to $55{ }^{\circ} \mathrm{C}$ has a significant accelerating effect on fatigue strength degradation. The infiltration of hydrones in salt solution is accelerated by the high temperature, which causes more rapid hydrolyzation of the $\mathrm{Si}-\mathrm{O}-\mathrm{Si}$ chemical bond between the fiber and the matrix, thereby leading to more local debonding areas on the fiber-matrix interface.

\subsection{Scanning electron microscope (SEM) analysis}

233 The microstructures of BFRP tendons after corrosion in salt solution are revealed through

234 SEM. The cross-sections for SEM analysis were cut from the middle portion of one FRP

235 tendon specimen to avoid the impact of concentration of corrosion at the two ends. The 236 control specimen without aging in salt solution shows an intact cross-section (Figure 9 (a)).

237 By contrast, the specimens aged at $55{ }^{\circ} \mathrm{C}$ for $63 \mathrm{~d}$ (group T55-D63) display the largest 238 corrosion areas. By amplifying these areas, several corrosive channels are observed, which 239 reflect the paths of salt solution corrosion from the surface to the inside (Figure 9(b)). The 240 corrosion damage degrees of the specimens in the groups of T55-D21, T55-D42 and 241 T40-D63 are significantly lower than that of T55-D63 (Figure 9(c)-(e)). Although debonding 242 areas are observed at the surface, the numbers of corrosive channels are not comparable to 
243 those of group T55-D63. For the specimens in group T25-D63, the fiber-matrix interface at

244 the surface is intact (Figure 9(f)), indicating that the corrosion rate of BFRP tendon in salt

245 solution is extremely slow at normal temperature $\left(25^{\circ} \mathrm{C}\right)$. Thus, high aging temperature and

246 long aging duration are two essential factors for the significant corrosive effects of salt

247 solution. The corrosion degrees of the specimens observed by SEM are consistent with the

248 fatigue strength degradation reflected by the experimental data in Section 4.5.

\subsection{Prediction of fatigue strength degradation at different temperatures}

\subsubsection{Arrhenius equation}

252

Practical infrastructures are exposed to different aging temperatures. Thus, the prediction of the fatigue strength degradation of BFRP tendons at different temperatures is necessary. This prediction is based on the Arrhenius equation [29], as expressed by

$$
k=A \exp \left(-E_{a} / R T\right)
$$

where $k=$ degradation rate, $A=$ constant related to the material and degradation process, $E_{a}=$ activation energy in $\mathrm{kJ} / \mathrm{mol}, R=$ gas constant in $\mathrm{kJ} / \mathrm{mol} \cdot \mathrm{K}$, and $T=$ absolute temperature, in $\mathrm{K}$.

Generally, for calculation convenience, the above Arrhenius equation can be transformed into

$$
\ln (1 / k)=E_{a} / R T-\ln A
$$

261 The prediction using the Arrhenius equation is based on the assumption that a single

262 dominant degradation mechanism exists with different aging temperatures and durations. In

263 this study, the temperatures were far lower than the glass transition temperature of the resin.

264 Thus, the above requirement can be easily achieved. 
267 To adopt the Arrhenius equation to predict fatigue strength at different temperatures, the 268 degradation of the fatigue strength with respect to aging duration should be clarified. The most commonly used degradation formula was proposed by Bank et al. [30] and has been adopted by many researchers $[31,32]$. The degradation formula is based on the following assumption:

$$
10^{Y} \propto \frac{1}{k t}
$$

where $Y=$ ratio of residual fatigue strength to the ultimate tensile strength $\left(f_{u}\right)$, and $t=$ aging duration. By substituting the Arrhenius equation into Eq. (5), it is deduced that

$$
Y \propto-\ln (t)+1 / T
$$

Thus, the degradation formula at a certain temperature is expressed by

$$
Y=a_{1}-b_{1} \ln (t)
$$

Where $a_{1}$ and $b_{1}$ are regression constants, and $t=$ service duration in days.

The results of the curve fitting are shown in Figure 10 and Table 5. The three fitting lines of the $Y$ - $\ln (t)$ relationship can be considered approximately parallel to each other, indicating that a single dominant degradation mechanism exists during the tests.

4.7.3 Prediction of the degradation law of fatigue strength at different local temperatures

In Eq. (6), a linear relationship exists between $Y$ and $1 / T$ at a certain aging duration $(t)$, as expressed by

$$
Y=\alpha+1000 \beta / T
$$


where $\alpha$ and $\beta$ are regression constants.

The prediction is conducted by plotting a series of lines describing the relationships between

289 the fatigue strength and 1000/T at different durations. Several durations were selected by

290 considering some representative service durations of infrastructure, i.e., 1, 5, 10, 20, 50 and

291100 years (Figure 11). The regression constants ( $\alpha$ and $\beta$ ) and regression coefficients are

292 shown in Table 6.

293 Using the prediction formula in Eq. (8), the values of fatigue strength are predicted under 294 different local temperatures at service durations of 1, 5, 10, 20, 50 and 100 years. The local temperatures are mainly dependent on the latitude. To simplify the analysis, temperatures in the northern hemisphere were adopted in this study. The annual temperature varies little

297 between $0^{\circ}$ and northern latitude (NL) $20^{\circ}$. NL $60^{\circ}$ is so close to the Arctic Circle that few 298 structures are distributed in regions with a latitude higher than NL $60^{\circ}$. Thus, the annual temperatures at $\mathrm{NL} 20^{\circ}, 40^{\circ}$ and $60^{\circ}$, equal to $26^{\circ} \mathrm{C}, 16^{\circ} \mathrm{C}$ and $6{ }^{\circ} \mathrm{C}$, respectively [33], were selected. The fatigue strength-service duration curves at the three temperatures are shown in

Figure 12. These curves decrease rapidly in the first several years and become stable after 20 years.

The prediction formula is expressed by

$$
Y=A_{l}-B_{l} \ln (t)
$$

305 where $A_{l}$ and $B_{l}=$ regression constants, and $t=$ service duration in years.

306 The values of $A_{l}, B_{l}$ and the regression coefficient for the prediction of the fatigue strength at 307 NL $20^{\circ}, 40^{\circ}$ and $60^{\circ}$ are shown in Table 7.

308 With Eq. (9), the fatigue strength of BFRP tendons can be predicted at different service 
310 to be $0.41,0.43$ and $0.45 f_{u}$, respectively, at $\mathrm{NL} 20^{\circ}, 40^{\circ}$ and $60^{\circ}$ after aging in marine

311 environments for 100 years. Although $0.5 f_{u}$ was considered to be the optimal stress level for

312 BFRP prestressed tendons $[10,34]$, the fatigue strength of $0.41 f_{u}$ is also acceptable for

313 prestressing use, which is larger than the maximum stress (approximately $0.3 f_{u}$ ) in FRP

314 cable-stayed bridges during service life [24]. The results provide guidance for the fatigue

315 design of BFRP tendons applied under a marine environment.

\section{5. Conclusions}

318 This paper comprehensively studied the fatigue behavior of BFRP tendons under a marine

319 environment. Fatigue tests of BFRP tendons were conducted after aging in a salt solution at

320 three different temperatures $\left(25,40\right.$ and $\left.55{ }^{\circ} \mathrm{C}\right)$ and durations $(21,42$ and $63 \mathrm{~d})$. The

321 degradation mechanism of fatigue behavior was clarified based on the analysis of the failure mode and previous studies. The effect of aging temperature on fatigue behavior degradation was analyzed from both experimental data and SEM analysis. Finally, the fatigue strength of BFRP tendons at different local temperatures was predicted with the Arrhenius equation. The main conclusions are listed as follows.

(1) Aging in salt solution allowed hydrones to infiltrate through the resin matrix on the surface and hydrolyze the $\mathrm{Si}-\mathrm{O}-\mathrm{Si}$ chemical bond between the fiber and the matrix, leading to local debonding of the fiber-matrix interface under cyclic loads, which was the main cause of the fatigue strength degradation of BFRP tendons under a marine environment. 
331 areas than the specimens in the other groups because the infiltration of hydrones in the salt

332 solution was accelerated by the high temperature, leading to more severe hydrolyzation of the

$333 \mathrm{Si}-\mathrm{O}-\mathrm{Si}$ chemical bond between the fiber and the matrix. The results of the SEM analysis

334 were consistent with the experimental data.

335 (3) Using the Arrhenius equation, the values of the fatigue strength of BFRP tendons were

336 predicted to be $0.41,0.43$ and $0.45 f_{u}$ at northern latitudes of $20^{\circ}, 40^{\circ}$ and $60^{\circ}$, respectively,

337 after aging in marine environments for 100 years. These results can serve as a guide for the

338 fatigue design of BFRP tendons under a marine environment.

339

340 


\section{$341 \quad$ Figure captions}

342 Figure 1 Anchorage for the fatigue test: (a) winding fiber sheet; (b) mold; (c) anchorage after

343 molding; (d) photograph of the anchorage

344 Figure 2 Corrosion test chamber: (a) external view; (b) internal view

345 Figure 3 LFV-1000 servo-hydraulic dynamic fatigue tester

346 Figure 4 Failure mode in the short-term tensile test

347 Figure 5 Failure mode in fatigue test: (a) initial failure; (b) ultimate failure

348 Figure 6 Schematic diagram of degradation

349 Figure 7 S-N curves for the test groups and control group

$350 \quad$ Figure 8 Fatigue strength-aging duration relation curves

351 Figure 9 SEM of specimens in the (a) control, (b) T55-D63, (c) T55-D42, (d) T55-D21, (e)

352 T40-D63, and (f) T25-D63 groups

353 Figure 10 Curve fitting for the $Y-\ln (t)$ relationship

354 Figure 11 Curve fitting for the $Y-1000 / T$ relationship

355 Figure 12 Fatigue strength-service duration curves

356

357 
359 Table 1 Aging procedures for the test groups

360 Table 2 Short-term tensile properties

361 Table 3 Fatigue lives of the specimens

362 Table 4 Prediction of the fatigue strength

363 Table 5 Values of $a_{1}, b_{1}$ and regression coefficient $\left(R^{2}\right)$

364 Table 6 Values of $\alpha, \beta$ and regression coefficient $\left(R^{2}\right)$

365 Table 7 Values of $A_{l}, B_{l}$ and regression coefficient $\left(R^{2}\right)$ 
Table 1 Aging procedures for the test groups

\begin{tabular}{cccc}
\hline Test group & $\begin{array}{c}\text { Aging temperature } \\
\left({ }^{\circ} \mathrm{C}\right)\end{array}$ & $\begin{array}{c}\text { Aging duration } \\
\text { (days) }\end{array}$ & $\begin{array}{c}\text { Number of } \\
\text { specimen }\end{array}$ \\
\hline T25-D21 & 25 & 21 & 5 \\
T25-D42 & 25 & 42 & 5 \\
T25-D63 & 25 & 63 & 5 \\
\hline T40-D21 & 40 & 21 & 5 \\
T40-D42 & 40 & 42 & 5 \\
T40-D63 & 40 & 63 & 5 \\
\hline T55-D21 & 55 & 21 & 5 \\
T55-D42 & 55 & 42 & 5 \\
T55-D63 & 55 & 63 & 5 \\
\hline
\end{tabular}


Table 2 Short-term tensile properties

\begin{tabular}{ccccc}
\hline Specimen number & $\begin{array}{c}\text { Tensile capacity } \\
F_{t}(\mathrm{kN})\end{array}$ & $\begin{array}{c}\text { Tensile strength } \\
f_{t}(\mathrm{MPa})\end{array}$ & $\begin{array}{c}\text { Elastic modulus } \\
E(\mathrm{GPa})\end{array}$ & $\begin{array}{c}\text { Fracture strain } \\
\varepsilon_{u}(\%)\end{array}$ \\
\hline BE-1* & 48.7 & 1784 & 53.9 & 3.31 \\
BE-2 & 45.7 & 1674 & 53.7 & 3.12 \\
BE-3 & 45.0 & 1648 & 54.0 & 3.05 \\
BE-4 & 46.6 & 1707 & 53.4 & 3.20 \\
BE-5 & 48.7 & 1784 & 53.3 & 3.35 \\
Mean value & 46.9 & 1719 & 53.7 & 3.20 \\
SD & 1.5 & 55.8 & 0.3 & 0.11 \\
CV & $3.25 \%$ & $3.25 \%$ & $0.51 \%$ & $3.48 \%$ \\
\hline
\end{tabular}

$* \mathrm{BE}$ is the abbreviation for basalt fiber and epoxy resin. 
Table 3 Fatigue lives of the specimens

\begin{tabular}{ccccccccc}
\hline Number & $\sigma_{\max }\left(f_{u}\right)$ & $N_{f}$ & Number & $\sigma_{\max }\left(f_{u}\right)$ & $N_{f}$ & Number & $\begin{array}{c}\sigma_{\max } \\
\left(f_{u}\right)\end{array}$ & $N_{f}$ \\
\hline T25-D21-1 & 0.70 & 96,609 & T40-D21-1 & 0.70 & 121,318 & T55-D21-1 & 0.70 & 83,203 \\
T25-D21-2 & 0.68 & 206,834 & T40-D21-2 & 0.68 & 158,927 & T55-D21-2 & 0.68 & 92,875 \\
T25-D21-3 & 0.65 & 212,196 & T40-D21-3 & 0.65 & 225,592 & T55-D21-3 & 0.65 & 184,531 \\
T25-D21-4 & 0.62 & 531,675 & T40-D21-4 & 0.62 & 517,708 & T55-D21-4 & 0.62 & 339,782 \\
T25-D21-5 & 0.60 & $1,173,542$ & T40-D21-5 & 0.60 & 896,298 & T55-D21-5 & 0.60 & 630,594 \\
\hline T25-D42-1 & 0.70 & 108,118 & T40-D42-1 & 0.70 & 79,096 & T55-D42-1 & 0.70 & 40,514 \\
T25-D42-2 & 0.68 & 117,534 & T40-D42-2 & 0.68 & 97,825 & T55-D42-2 & 0.68 & 52,645 \\
T25-D42-3 & 0.65 & 157,506 & T40-D42-3 & 0.65 & 106,278 & T55-D42-3 & 0.65 & 85,423 \\
T25-D42-4 & 0.62 & 342,359 & T40-D42-4 & 0.62 & 315,201 & T55-D42-4 & 0.62 & 210,362 \\
T25-D42-5 & 0.60 & 888,002 & T40-D42-5 & 0.60 & 576,966 & T55-D42-5 & 0.60 & 430,136 \\
\hline T25-D63-1 & 0.70 & 70,846 & T40-D63-1 & 0.70 & 48,623 & T55-D63-1 & 0.70 & 27,378 \\
T25-D63-2 & 0.68 & 88,521 & T40-D63-2 & 0.68 & 65,549 & T55-D63-2 & 0.68 & 45,168 \\
T25-D63-3 & 0.65 & 126,699 & T40-D63-3 & 0.65 & 83,451 & T55-D63-3 & 0.65 & 58,481 \\
T25-D63-4 & 0.62 & 289,230 & T40-D63-4 & 0.62 & 215,031 & T55-D63-4 & 0.62 & 152,544 \\
T25-D63-5 & 0.60 & 786,747 & T40-D63-5 & 0.60 & 497,527 & T55-D63-5 & 0.60 & 320,978 \\
\hline
\end{tabular}


Table 4 Prediction of the fatigue strength

\begin{tabular}{ccccc}
\hline Test group & $a$ & $b$ & Regression coefficient $\left(R^{2}\right)$ & Fatigue strength $\left(f_{u}\right)$ \\
\hline Control [12] & 1.2014 & 0.042 & 0.8972 & 0.592 \\
\hline T25-D21 & 1.1688 & 0.041 & 0.9254 & 0.574 \\
T25-D42 & 1.1885 & 0.044 & 0.8819 & 0.550 \\
T25-D63 & 1.1338 & 0.04 & 0.9172 & 0.550 \\
\hline T40-D21 & 1.2596 & 0.048 & 0.9655 & 0.563 \\
T40-D42 & 1.1929 & 0.045 & 0.8905 & 0.540 \\
T40-D63 & 1.1348 & 0.041 & 0.9241 & 0.540 \\
\hline T55-D21 & 1.2270 & 0.047 & 0.9752 & 0.545 \\
T55-D42 & 1.1274 & 0.041 & 0.9653 & 0.533 \\
T55-D63 & 1.1102 & 0.041 & 0.9554 & 0.515 \\
\hline
\end{tabular}


Table 5

Table 5 Values of $a_{1}, b_{1}$ and regression coefficient $\left(R^{2}\right)$

\begin{tabular}{cccc}
\hline Temperature $\left({ }^{\circ} \mathrm{C}\right)$ & $a_{1}$ & $b_{1}$ & $R^{2}$ \\
\hline 25 & 0.6426 & 0.0232 & 0.87 \\
40 & 0.6287 & 0.0223 & 0.87 \\
55 & 0.6265 & 0.0262 & 0.93 \\
\hline
\end{tabular}


Table 6 Values of $\alpha, \beta$ and regression coefficient $\left(R^{2}\right)$

\begin{tabular}{cccc}
\hline Service duration (year) & $\alpha$ & $\beta$ & $R^{2}$ \\
\hline 1 & 0.1421 & 0.1093 & 0.91 \\
5 & 0.0546 & 0.1246 & 0.86 \\
10 & 0.0169 & 0.1312 & 0.85 \\
20 & -0.0208 & 0.1378 & 0.83 \\
50 & -0.0706 & 0.1465 & 0.81 \\
100 & -0.1083 & 0.1572 & 0.80 \\
\hline
\end{tabular}


Table 7 Values of $A_{l}, B_{l}$ and regression coefficient $\left(R^{2}\right)$

\begin{tabular}{ccccc}
\hline Northern latitude $\left({ }^{\circ}\right)$ & Annual temperature $\left({ }^{\circ} \mathrm{C}\right)$ & $A_{l}$ & $B_{l}$ & $R^{2}$ \\
\hline 20 & 26 & 0.5045 & 0.021 & 0.98 \\
40 & 16 & 0.5171 & 0.019 & 0.98 \\
60 & 6 & 0.5305 & 0.018 & 0.98 \\
\hline
\end{tabular}




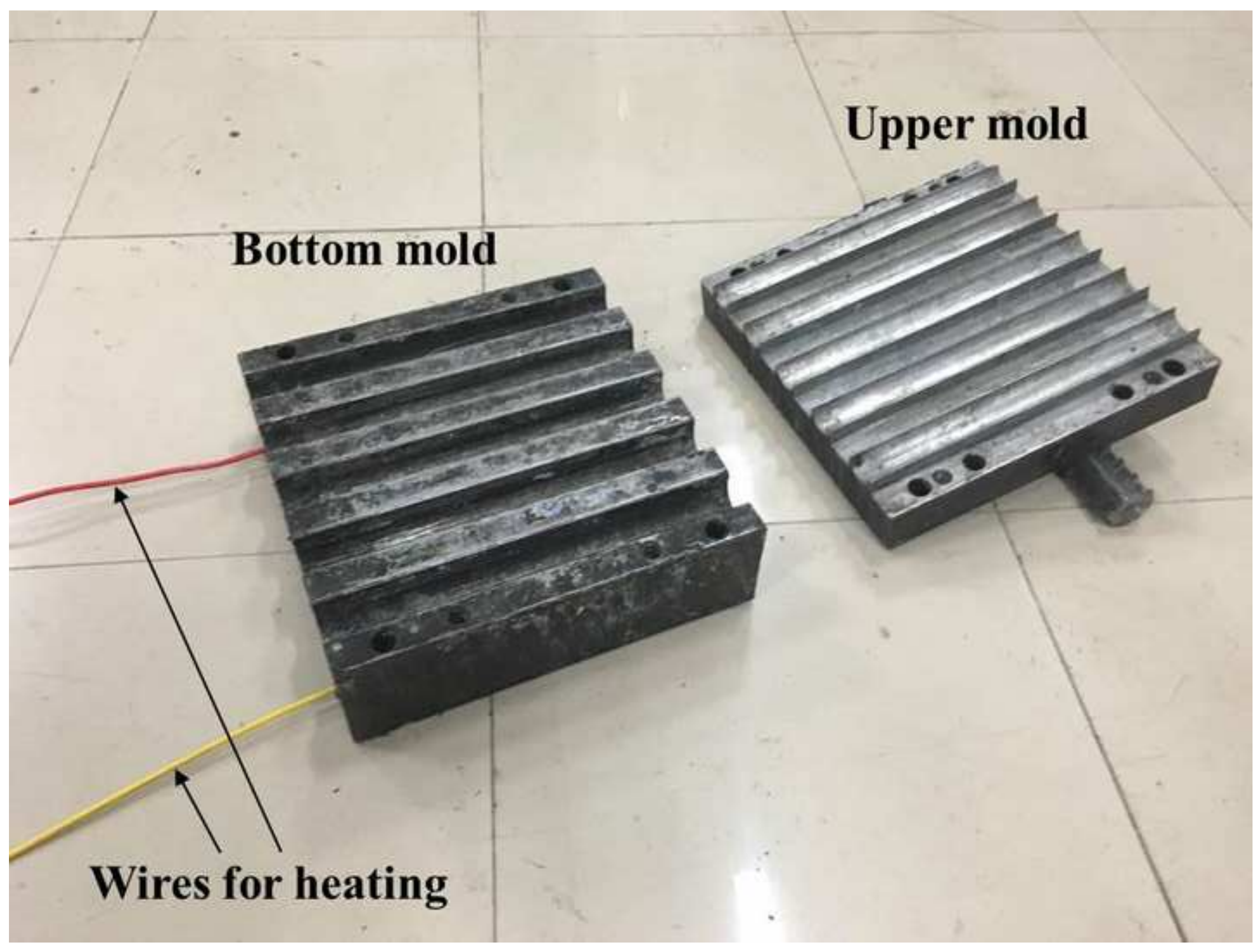

\section{Upper mold}




\section{Conical transition section}

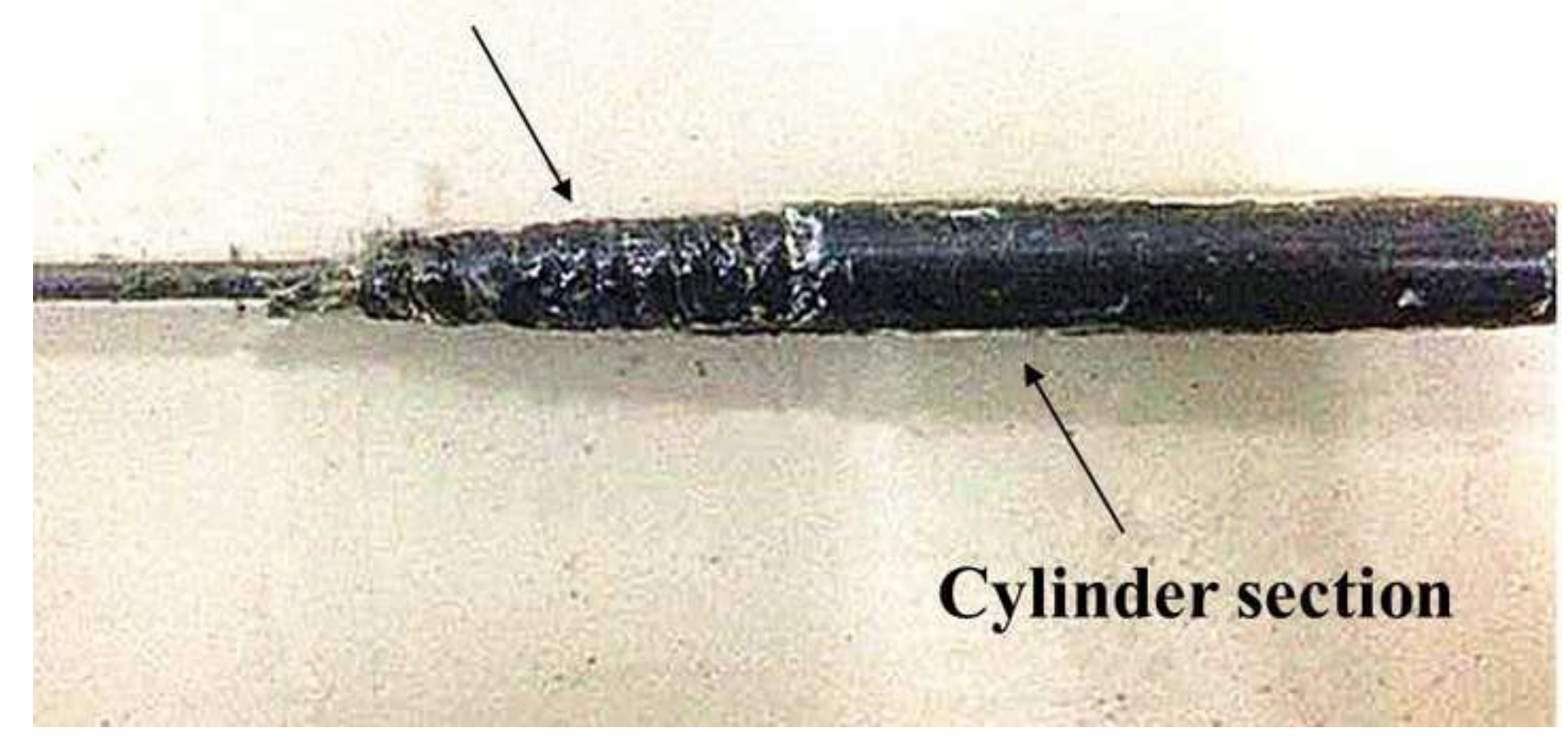

\section{Cylinder section}

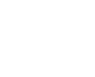




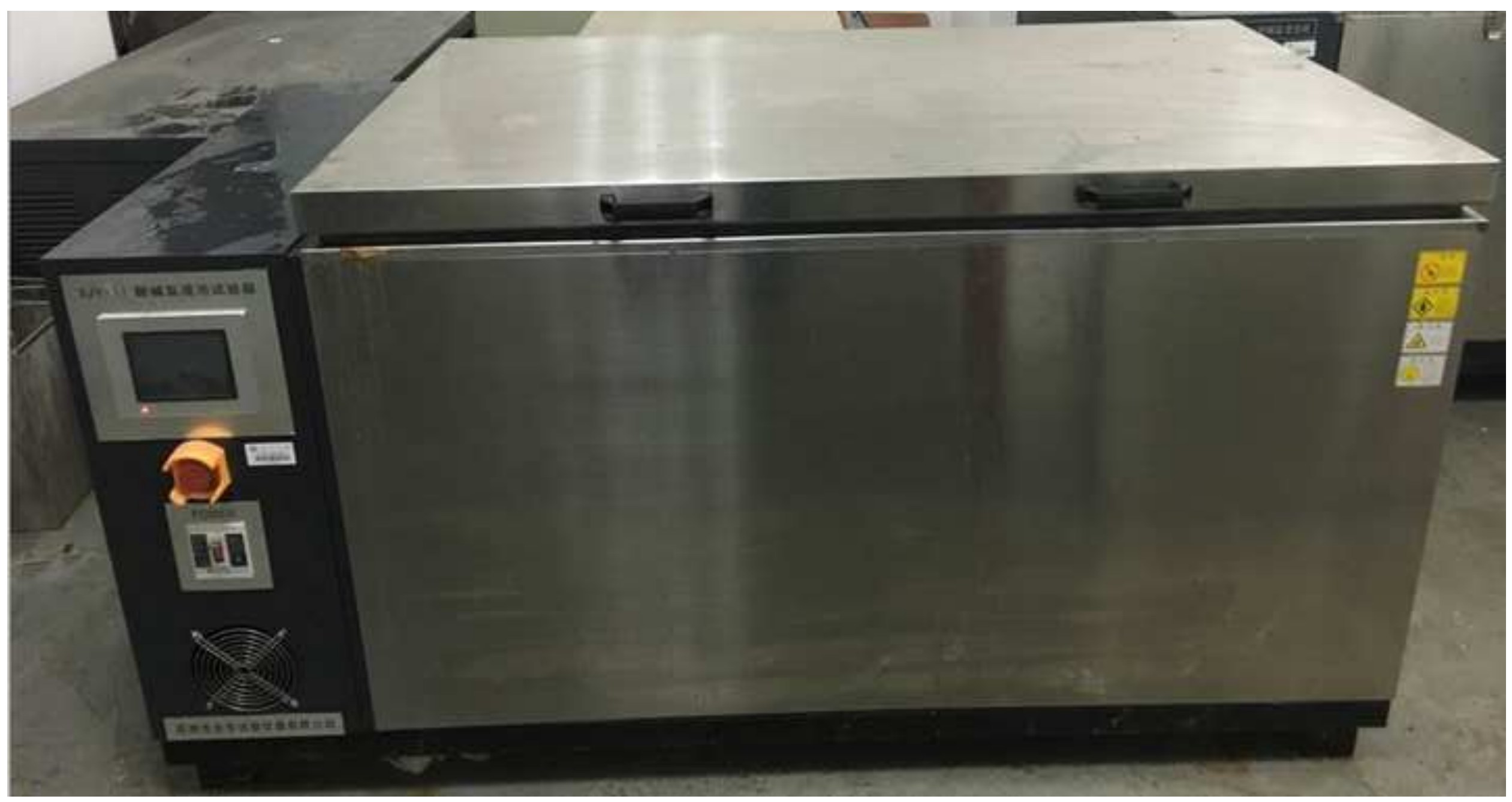




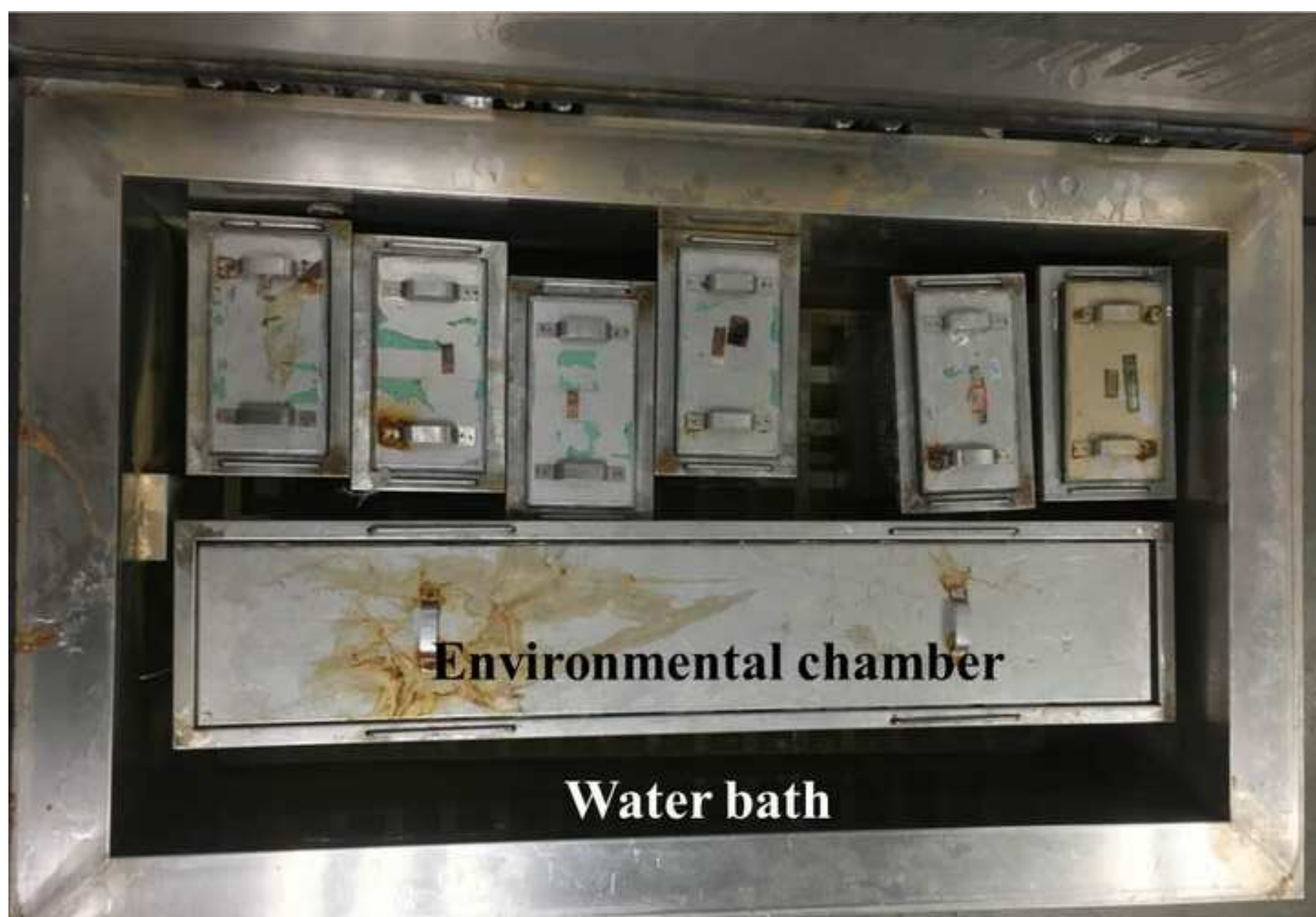

Water bath 


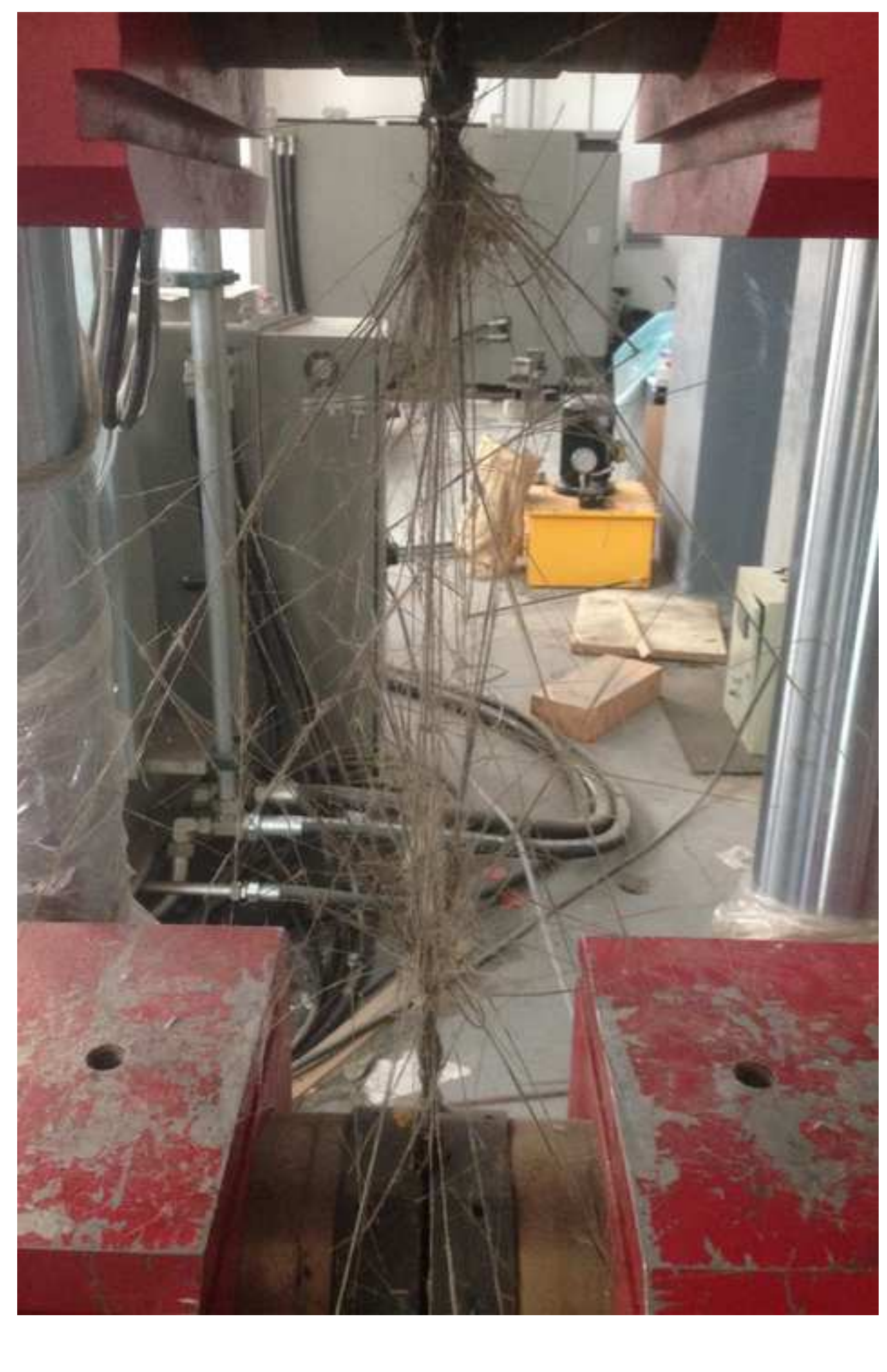

Figure 4

4


Figure 5(b)

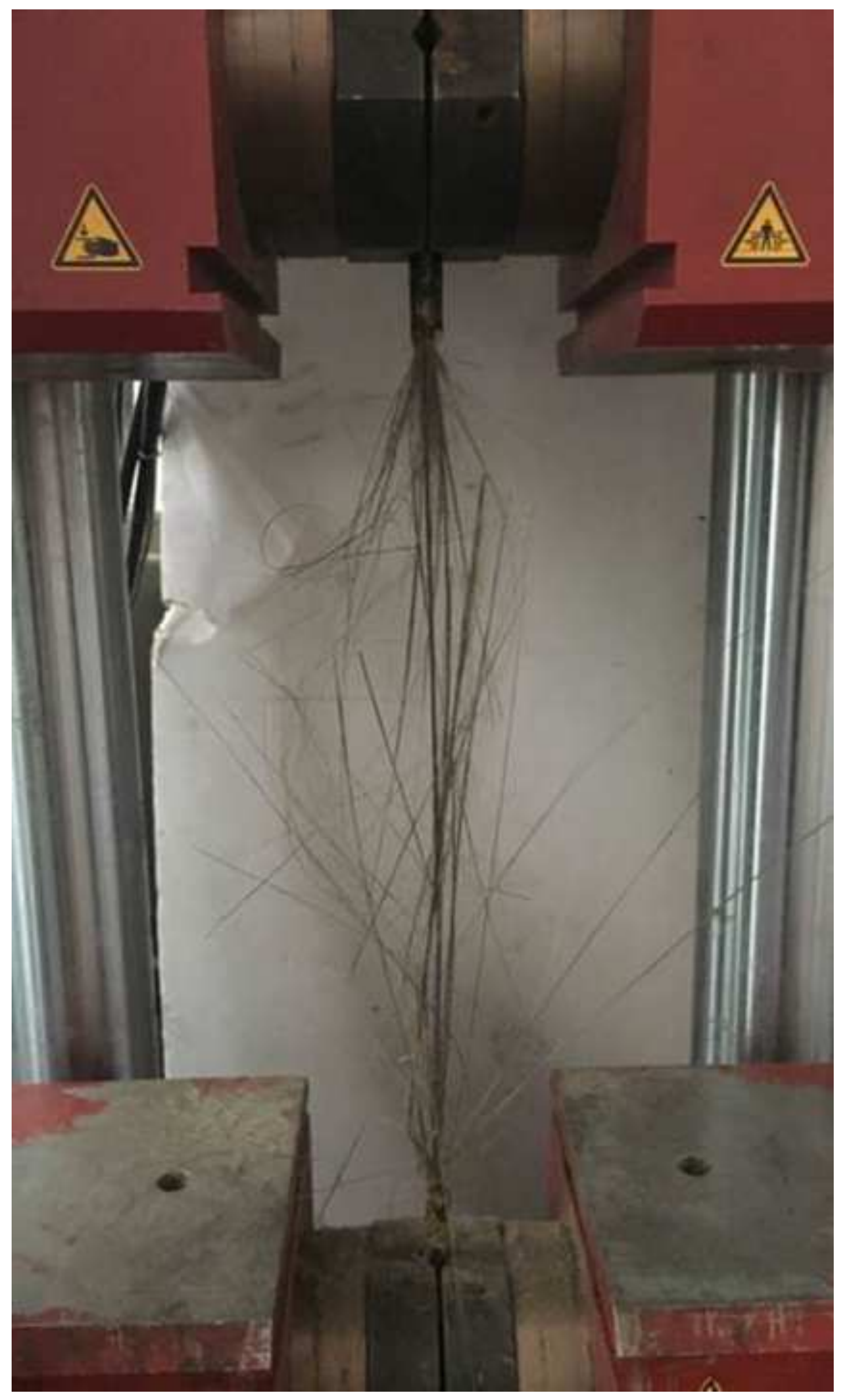




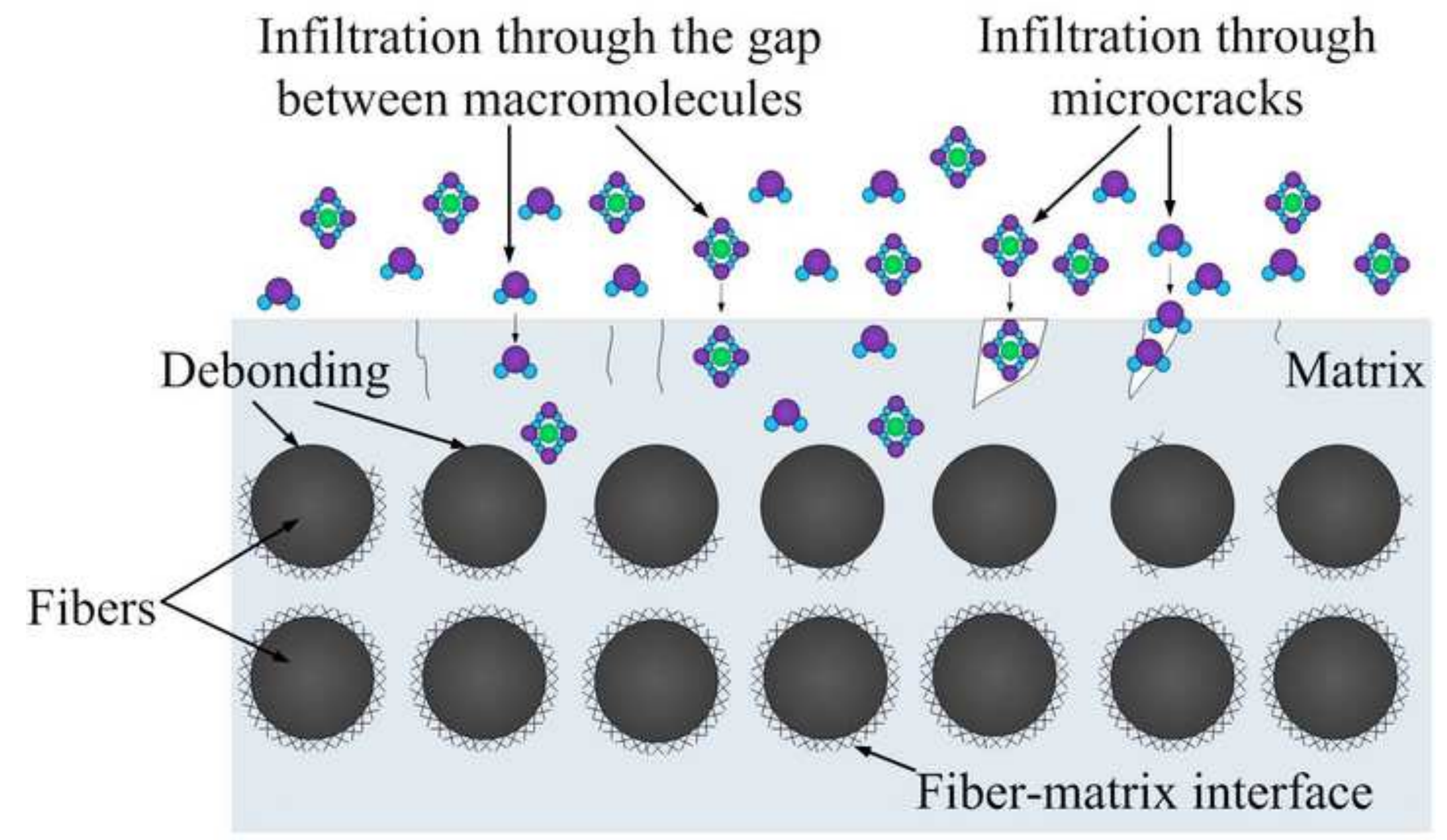

a Hydrone

- Chloride ion

Infiltration through the gap between macromolecules
Infiltration through microcracks 


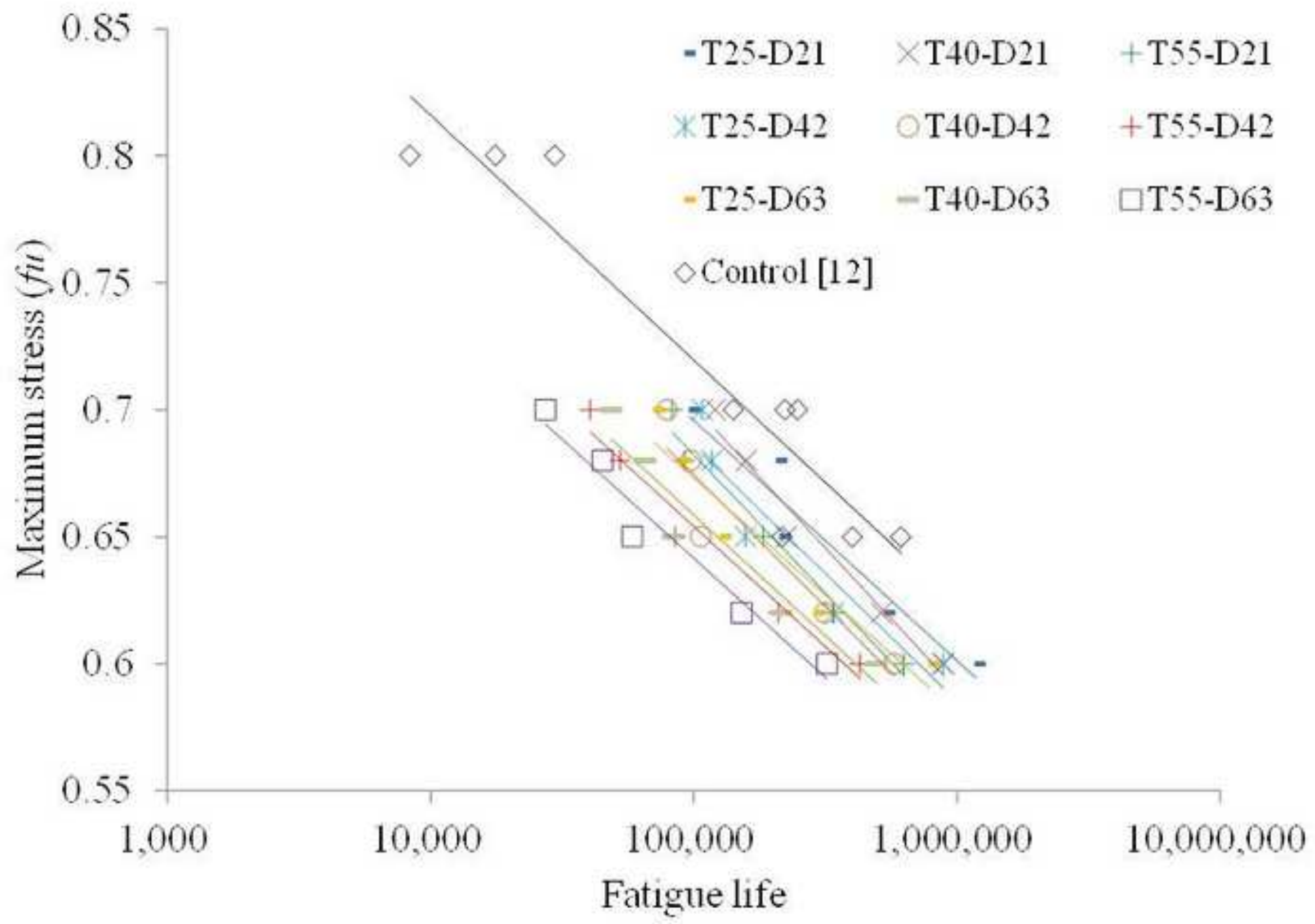




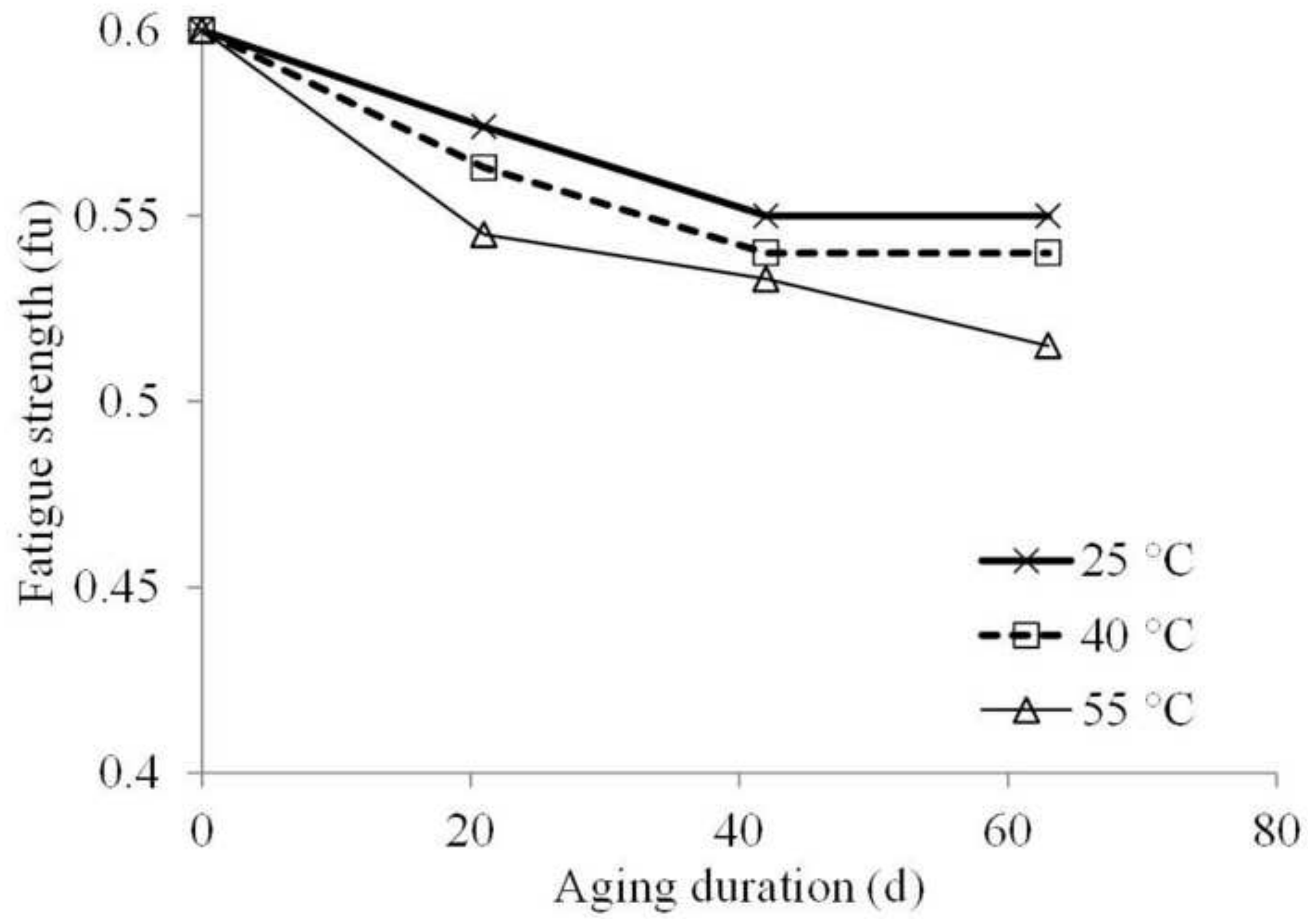




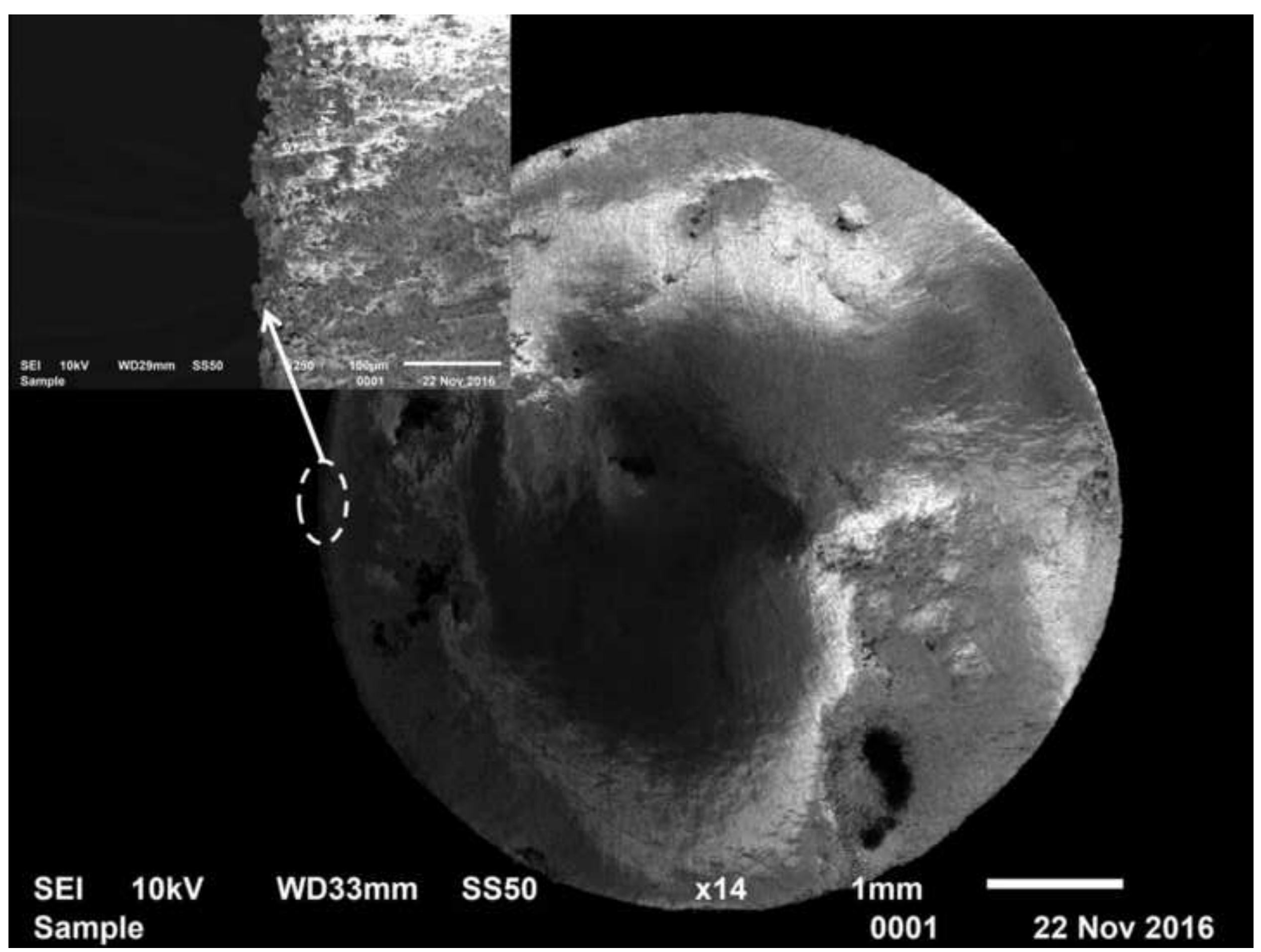




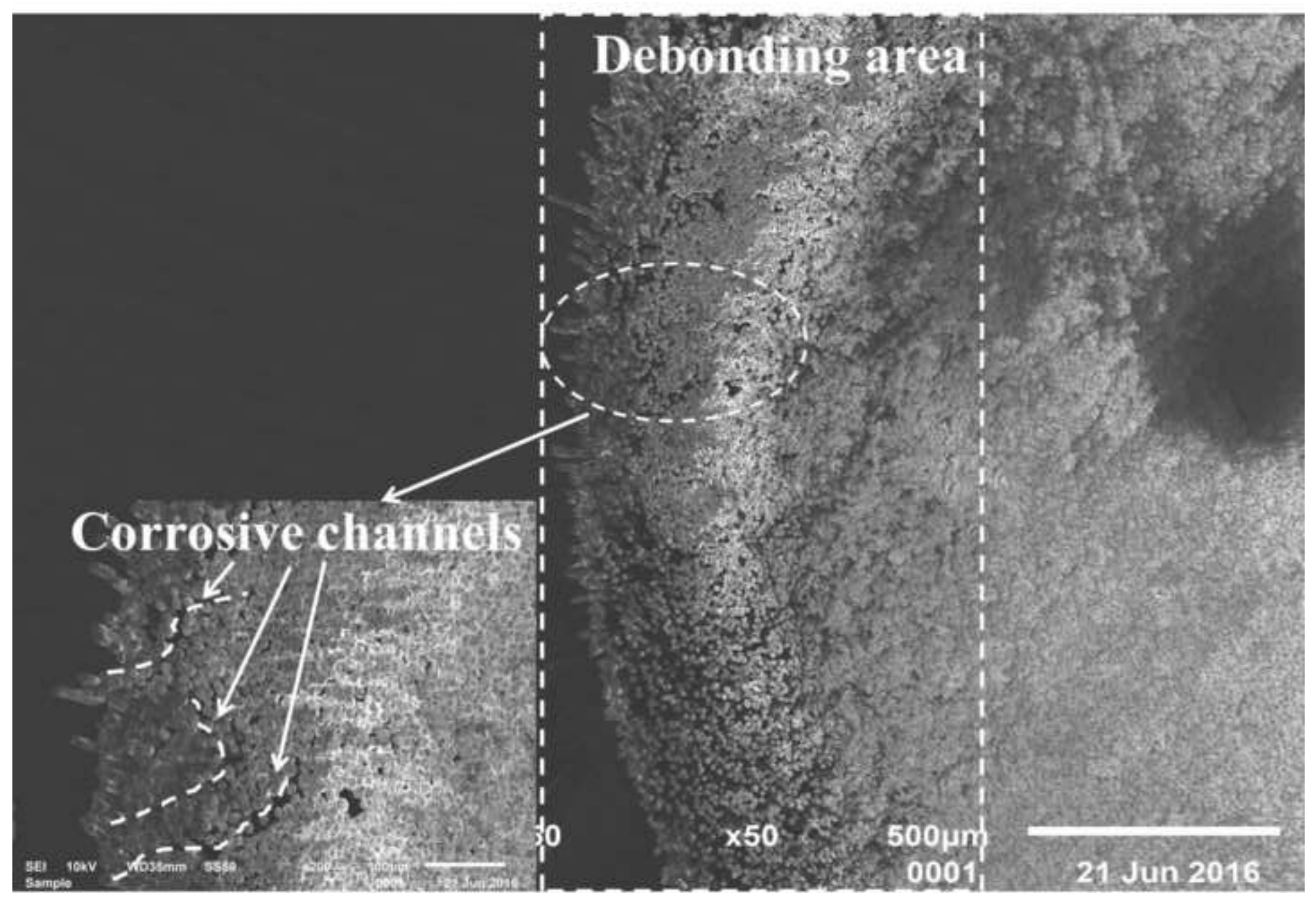

Corrosive chainrels : 21 Jun 2016

\section{Deboncing area:}

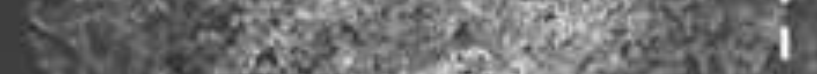

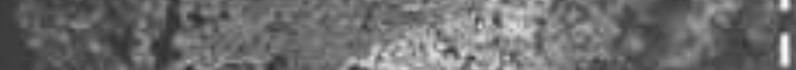

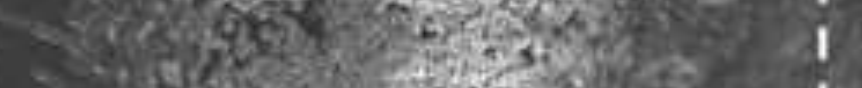

$1,-7-x+3 x+1$

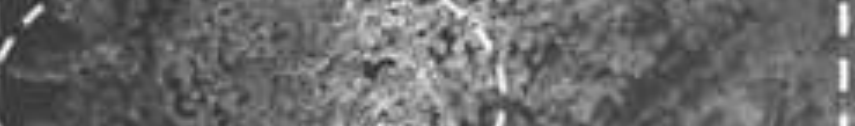

$i^{2}$

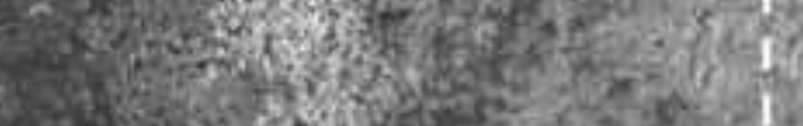

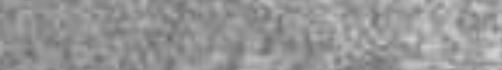




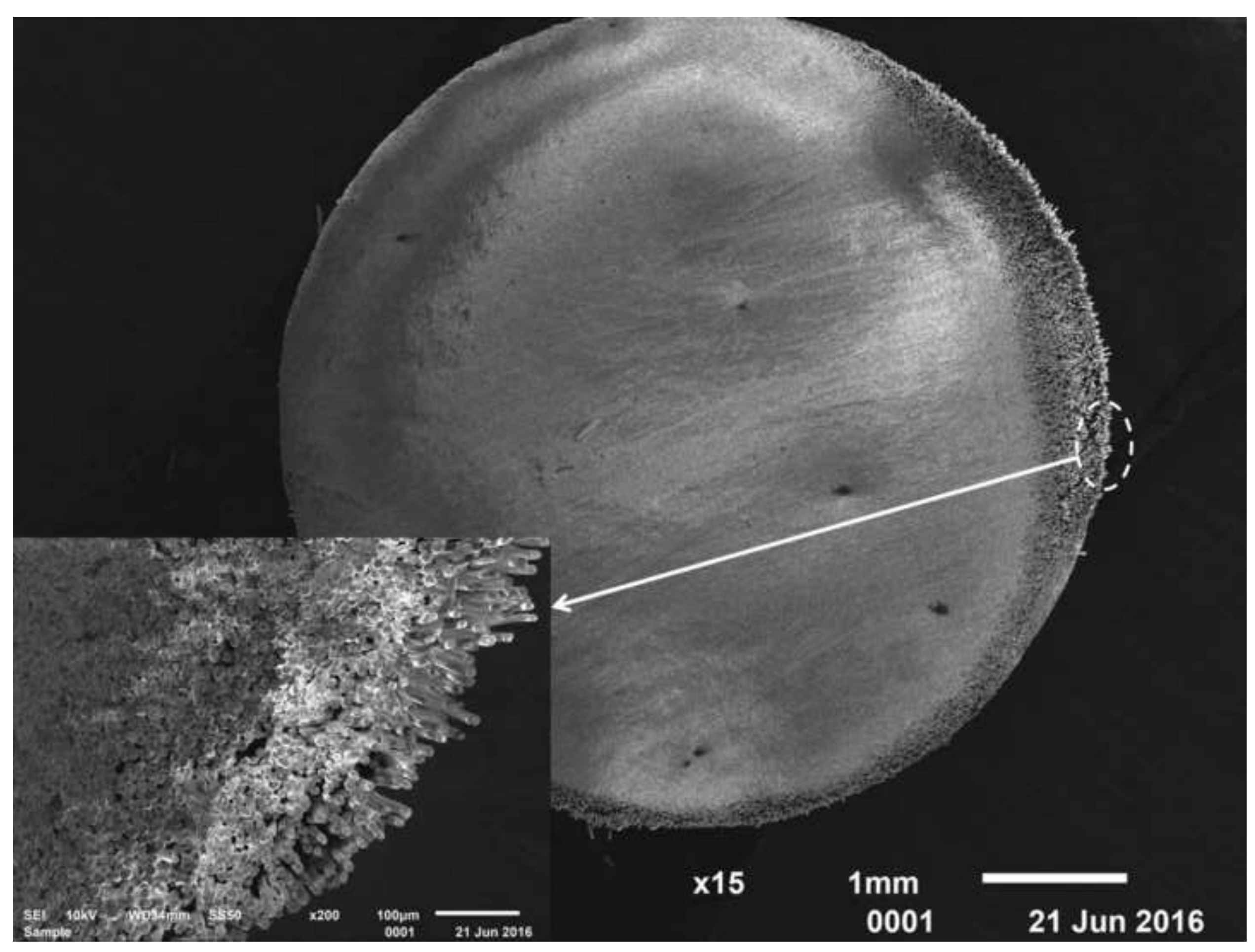




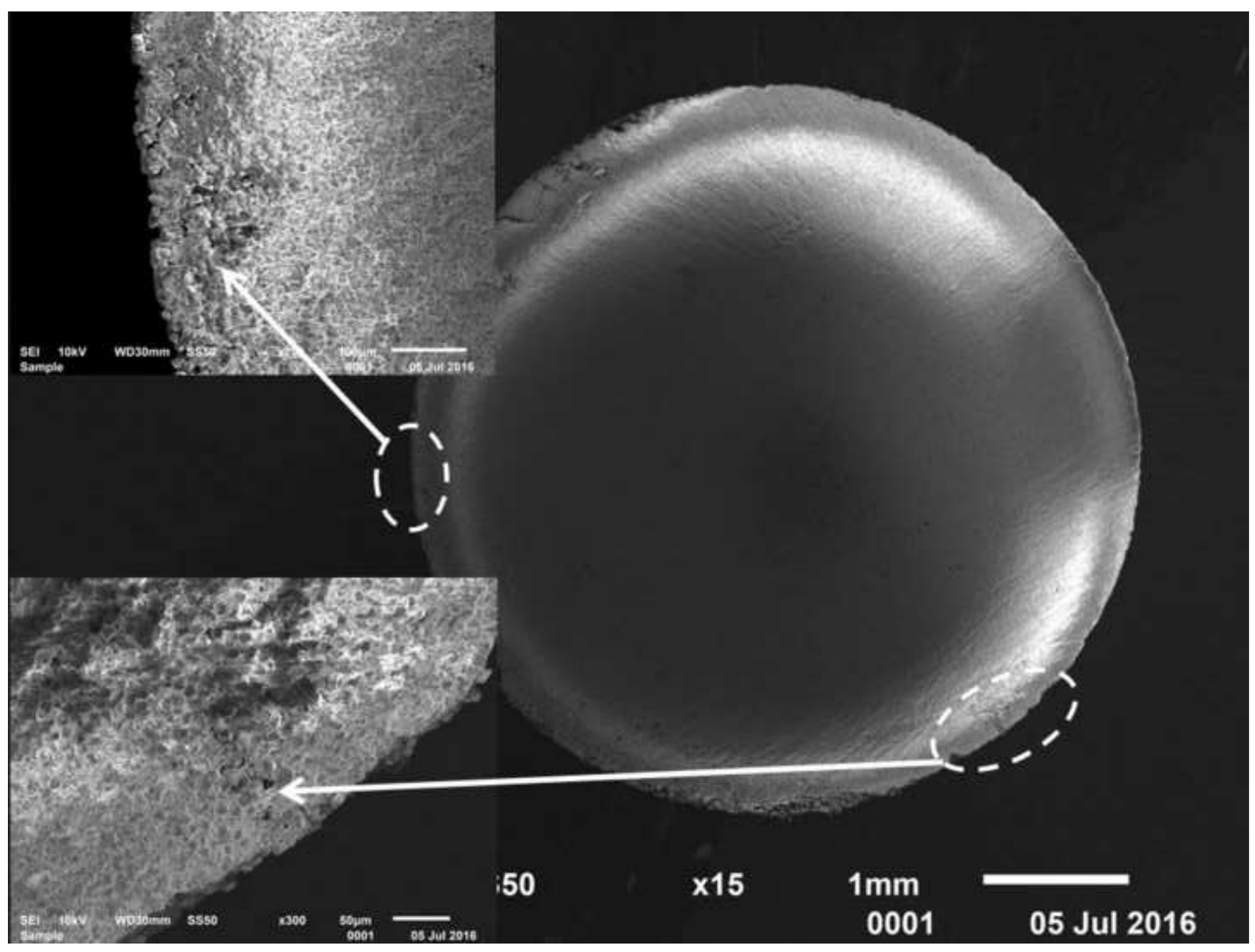




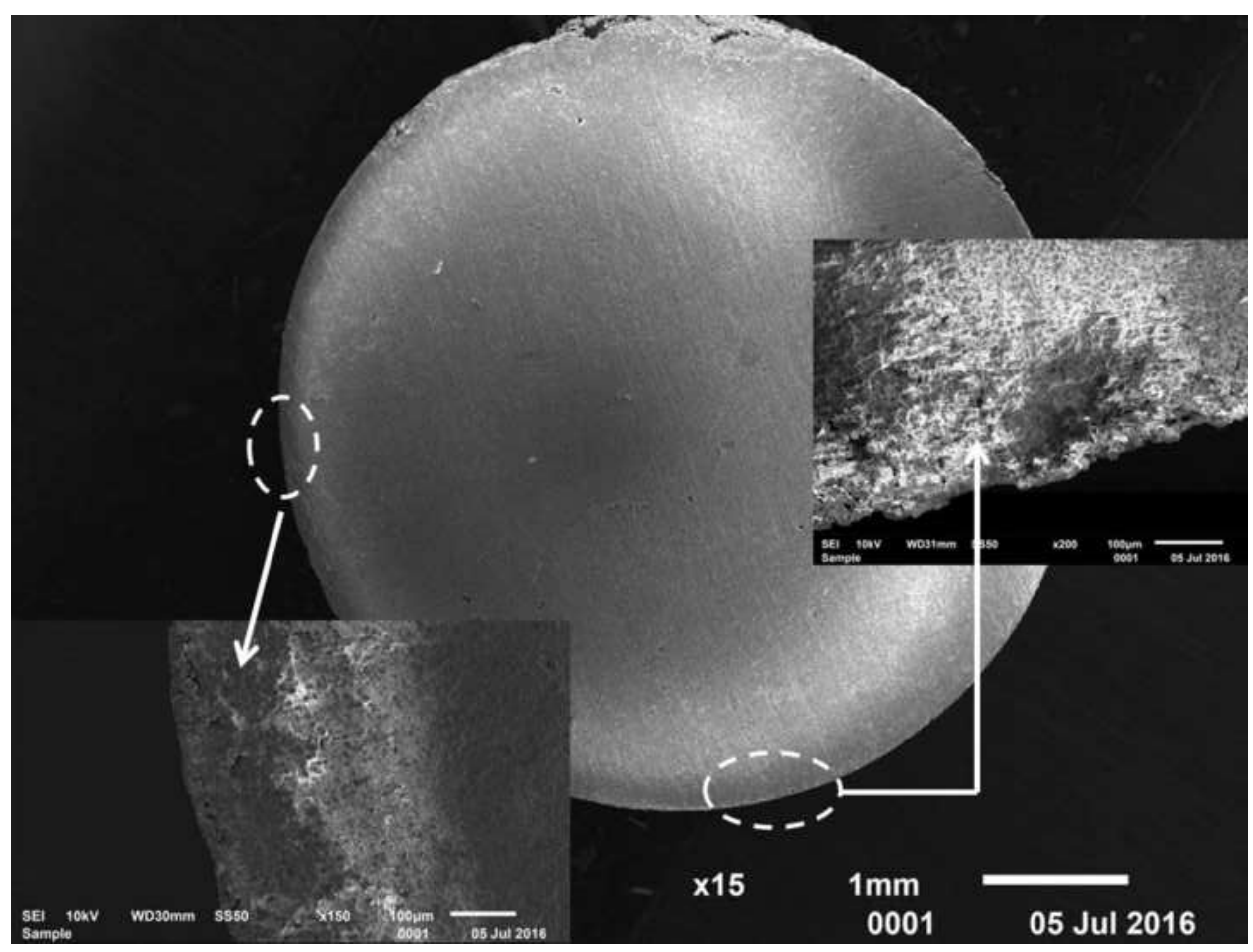




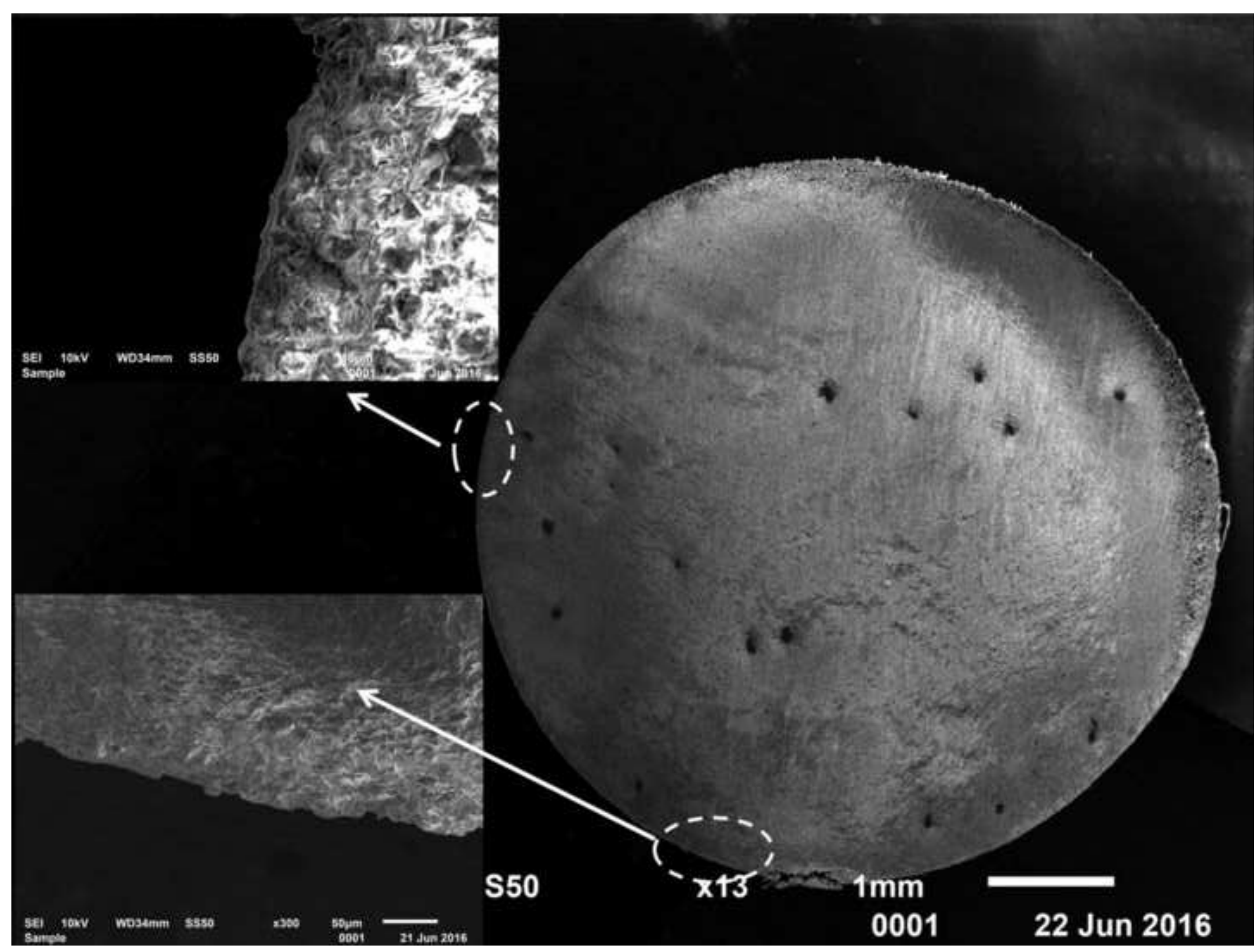




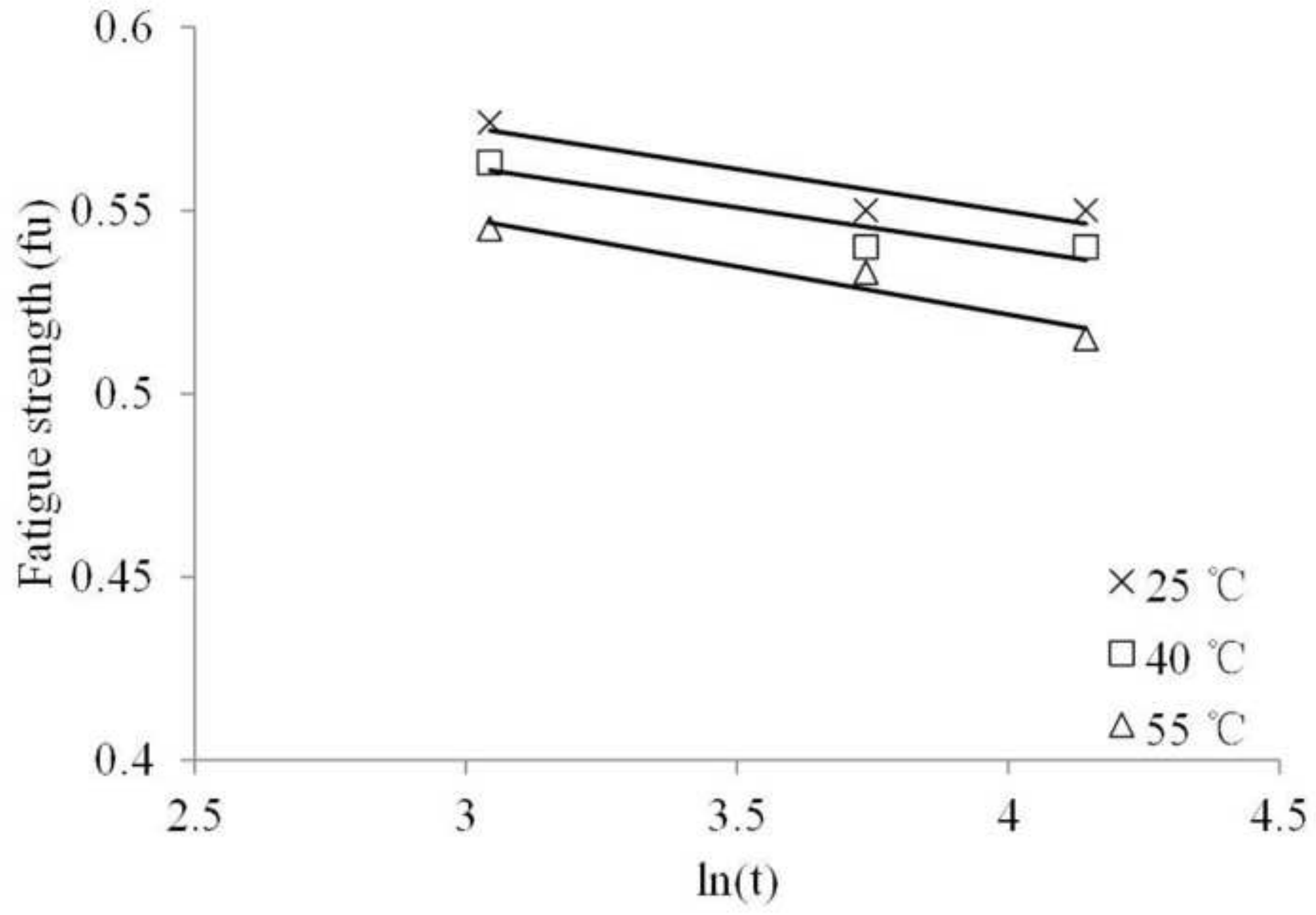




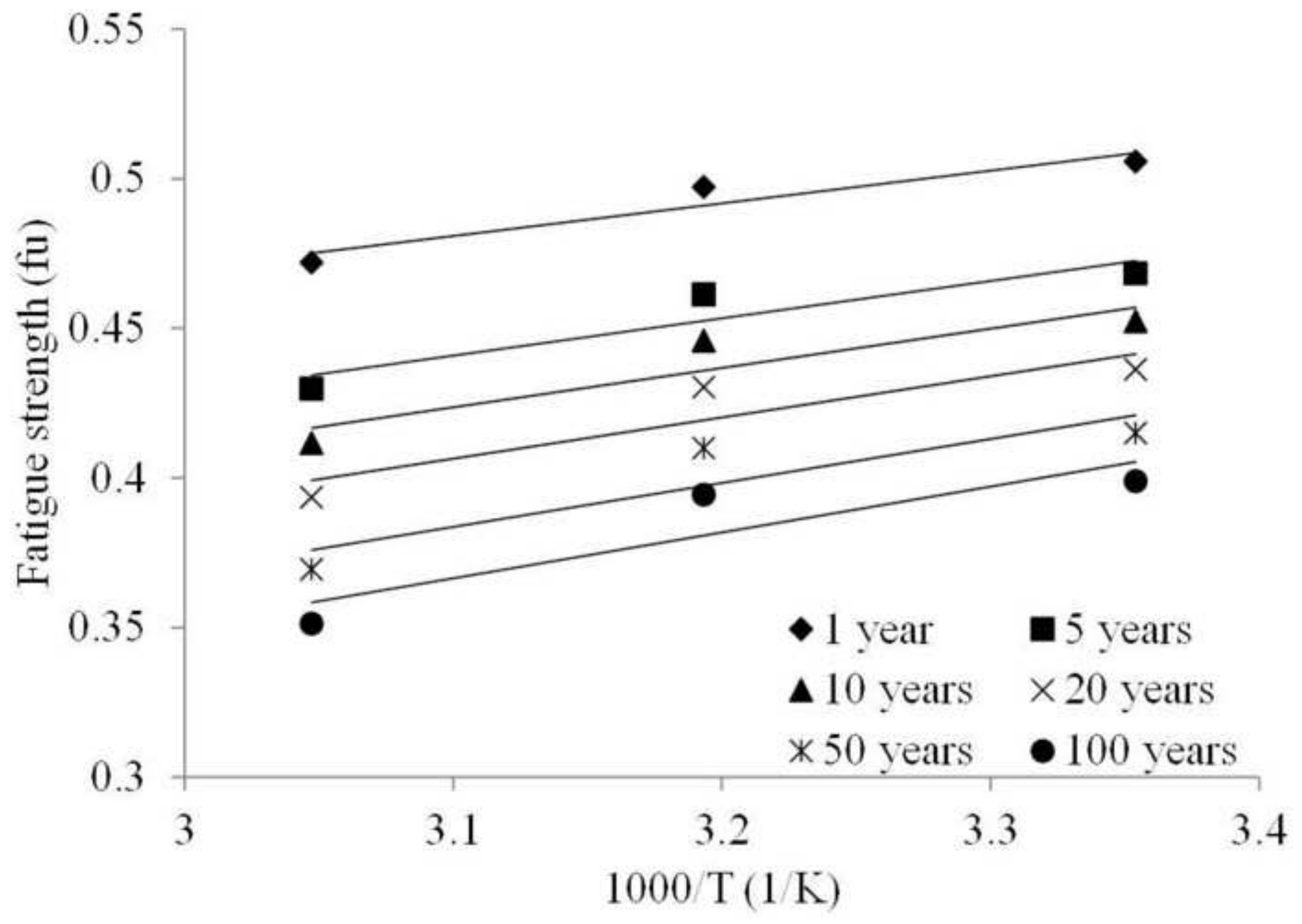




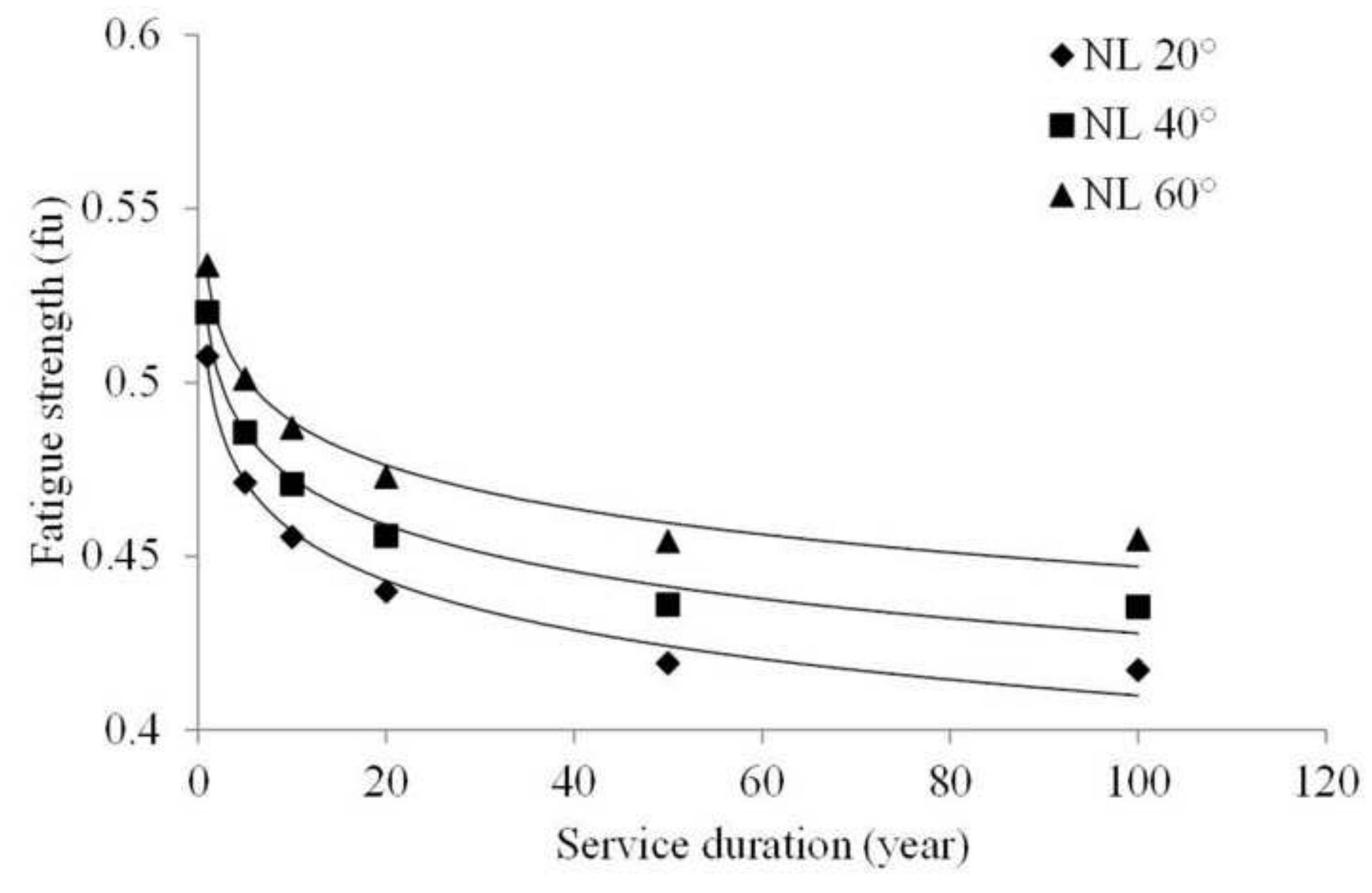

